\title{
Nonlinear Hybrid Procedures for Solving Some Nonlinear Equations
}

\author{
Bouchta RHANIZAR
}

Correspondence: Departement of Mathematics, Ecole Normale Supérieure, University Mohammed V of Rabat, Morocco

Received: September 3, 2019 Accepted: October 10, 2019 Online Published: October 28, 2019

doi:10.5539/jmr.v11n6p8 URL: https://doi.org/10.5539/jmr.v11n6p8

\begin{abstract}
The goal of this paper is to study a classic problem used in several fields such as science and engeneering. It's solving nonlinear equations:

$$
f(x)=0
$$

where $f: \mathbb{R} \longrightarrow \mathbb{R}$ is considered of class $C^{1}$ on the interval $I$ containing $x^{*}$ the solution of (1).

We propose in this research a new method for solving nonlinear equations. A convergence acceleration result is established and numerical examples are given.
\end{abstract}

Keywords: hybrid procedures, nonlinear equations

\section{Introduction}

Nonlinear equations are widely used to mathematically model many scientific computing problems. A large number of works have studied the resolution of nonlinear equations using Newton's method and its variants (Chun, 2007; Dennis \& Schnabel, 1983; Frontini \& Sormani, 2003; Ortega \& Rheinboldt, 1970). Newton's method is defined as follows (Dennis \& Schnabel, 1983; Ortega \& Rheinboldt):

$$
x_{n+1}=x_{n}-\frac{f\left(x_{n}\right)}{f^{\prime}\left(x_{n}\right)}, x_{0} \in I
$$

and

$$
\left|x_{n+1}-x^{*}\right| \leq C\left|x_{n}-x^{*}\right|^{2}
$$

The advantage is its quadratic convergence (Dennis \& Schnabel, 1983; Ortega \& Rheinboldt), but its major drawback is calculating the derivative for each iteration (Dennis \& Schnabel, 1983). When the function $f$ is not explicitly defined, the derivative is not always obtainable.

Our objective is to use hybrid procedures (Brezinski \& Chehab, 1998) to build a method whose convergence is at least quadratic, without computing the derivative for each iteration. Hybrid procedures were used by C. Brezinski and J.-P. Chehab in (Brezinski \& Chehab, 1998) for solving fixed point problems. They were also studied by B. Rhanizar, In (Rhanizar, 1999) for solving optimization problems.

Let $x^{\prime}$ and $x^{\prime \prime}$ be two approximate solutions for the equation (1), hybrid procedures construct a new approximate solution $y$ defined by:

$$
y=\alpha x^{\prime \prime}+(1-\alpha) x^{\prime}
$$

The parameter $\alpha$ is chosen to minimise the absolute value of the residual $\rho$ defined by:

$$
\rho=\alpha f\left(x^{\prime \prime}\right)+(1-\alpha) f\left(x^{\prime}\right)
$$

Let $x_{n}$ be an approximate solution to the equation (1), we consider the new approximate solution $y_{n}$ defined by:

$$
y_{n}=x_{n}+h f\left(x_{n}\right), \quad n \geq 0 \text { with } 0<|h| \leq 1
$$

We assume that:

$$
x_{n+1}=\alpha_{n} x_{n}^{\prime \prime}+\left(1-\alpha_{n}\right) x_{n}^{\prime}
$$

where the approximate solutions $x_{n}^{\prime}$ and $x_{n}^{\prime \prime}$ are given by: $x_{n}^{\prime}=x_{n}$ and $x_{n}^{\prime \prime}=y_{n}$ 
It is easy to see that the approximation defined by hybrid procedures will be given by:

$$
x_{n+1}=x_{n}-h \frac{f\left(x_{n}\right)}{f\left(x_{n}+h f\left(x_{n}\right)\right)-f\left(x_{n}\right)} f\left(x_{n}\right)
$$

\section{Convergence Study}

We have the following theorem:

Theorem 1 Let $f$ be of class $C^{2}$ on the interval I containing $x^{*}$ and suppose that there exists $m, M$ and $K$ such that:

$$
m \leq\left|f^{\prime}(x)\right| \leq M \text { et }\left|f^{\prime \prime}(x)\right| \leq K \forall x \in I
$$

Then:

1. There exists a neighborhood of $x^{*}$ such that, for every $x_{0}$ belonging to this neighborhood the sequence $\left(x_{n}\right)$ converges to $x^{*}$.

2. $\exists C_{1}>0$ such that:

where $C_{1}=\frac{K}{m}(1+|h| M)$

$$
\left|x_{n+1}-x^{*}\right| \leq C_{1}\left|x_{n}-x^{*}\right|^{2}
$$

Proof. Using the mean value theorem to $f$, we have:

$$
\begin{gathered}
f\left(x_{n}\right)=f^{\prime}\left(\beta_{n}\right)\left(x_{n}-x^{*}\right) \\
f\left(x_{n}+h f\left(x_{n}\right)\right)-f\left(x_{n}\right)=f^{\prime}\left(\alpha_{n}\right) h f\left(x_{n}\right)
\end{gathered}
$$

where:

$$
\begin{aligned}
\beta_{n} & \left.=x^{*}+s_{n}\left(x_{n}-x^{*}\right), \quad s_{n} \in\right] 0,1[ \\
\alpha_{n} & \left.=x_{n}+t_{n} h f\left(x_{n}\right), \quad t_{n} \in\right] 0,1[ \\
& =x_{n}+t_{n} h f^{\prime}\left(\beta_{n}\right)\left(x_{n}-x^{*}\right) .
\end{aligned}
$$

And by (2) and (4), we deduced:

$$
\left(x_{n+1}-x^{*}\right)=\left(x_{n}-x^{*}\right)-\frac{f\left(x_{n}\right)}{f^{\prime}\left(\alpha_{n}\right)}
$$

Then by (3) we have:

$$
\left(x_{n+1}-x^{*}\right) f^{\prime}\left(\alpha_{n}\right)=\left(x_{n}-x^{*}\right) f^{\prime}\left(\alpha_{n}\right)-f^{\prime}\left(\beta_{n}\right)\left(x_{n}-x^{*}\right)
$$

By applying the mean value theorem to $f^{\prime}$ and by using (5) and (6) we get:

$$
\left(x_{n+1}-x^{*}\right) f^{\prime}\left(\alpha_{n}\right)=\left(x_{n}-x^{*}\right)^{2} f^{\prime \prime}\left(\gamma_{n}\right)\left(1-s_{n}+t_{n} h f^{\prime}\left(\beta_{n}\right)\right)
$$

which gives:

$$
x_{n+1}-x^{*}=\left(x_{n}-x^{*}\right)^{2} \frac{f^{\prime \prime}\left(\gamma_{n}\right)}{f^{\prime}\left(\alpha_{n}\right)}\left(1-s_{n}+t_{n} h f^{\prime}\left(\beta_{n}\right)\right)
$$

i.e.

$$
\left|x_{n+1}-x^{*}\right| \leq C_{1}\left|x_{n}-x^{*}\right|^{2}
$$

where: $C_{1}=\frac{K}{m}(1+|h| M)$ 
We deduced then by induction that:

$$
C_{1}\left|x_{n}-x^{*}\right| \leq\left[C_{1}\left|x_{O}-x^{*}\right|\right]^{2^{n}}
$$

where $x_{0}$ is chosen to verify: $C_{1}\left|x_{O}-x^{*}\right|<1$

Thus, from (7) and (8), the sequence $x_{n}$ converges to the solution of the equation (1) and the convergence is quadratic.

\section{A Composite Method}

We set:

$$
y_{n}=x_{n+1}
$$

where $x_{n+1}$ is given by (2) and let we apply one more time hybrid procedures, we obtain then a new approximation

$x_{n+1}=\alpha_{n} x_{n}^{\prime \prime}+\left(1-\alpha_{n}\right) x_{n}^{\prime}$

where the approximate solutions $x_{n}^{\prime}$ and $x_{n}^{\prime \prime}$ are given by: $x_{n}^{\prime}=x_{n}$ and $x_{n}^{\prime \prime}=y_{n}$

The equation (2) implies that the approximate solution defined by hybrid procedures will be given by:

$$
x_{n+1}=x_{n}-h \frac{f\left(x_{n}\right)}{f\left(x_{n}+h f\left(x_{n}\right)\right)-f\left(x_{n}\right)} \frac{f\left(x_{n}\right)}{f\left(y_{n}\right)-f\left(x_{n}\right)}
$$

We have the following theorem:

Theorem 2 Under the assumptions of theorem 1, we have:

1. There exists a neighborhood of $x^{*}$ such that, for every $x_{0}$ belonging to this neighborhood the sequence $\left(x_{n}\right)$ converges to $x^{*}$.

2. $\exists C_{2}>0$ such that:

$$
\left|x_{n+1}-x^{*}\right| \simeq C_{2}\left|\left(x_{n}-x^{*}\right)\right|^{3}
$$

where $C_{2}=\frac{K^{2}}{2 m^{2}}(1+|h| M)$

Proof. By (2), (9) and (10), we have:

$$
\left(x_{n+1}-x^{*}\right)=\frac{\left(x_{n}-x^{*}\right) f\left(y_{n}\right)-\left(y_{n}-x^{*}\right) f\left(x_{n}\right)}{f\left(y_{n}\right)-f\left(x_{n}\right)}
$$

Then, by applying Taylor formula to $f$ for the order 2, we have:

$$
f\left(x_{n}\right)=f^{\prime}\left(x^{*}\right)\left(x_{n}-x^{*}\right)+\frac{f^{\prime \prime}\left(x^{*}\right)}{2}\left(x_{n}-x^{*}\right)^{2}+o\left(\left|\left(x_{n}-x^{*}\right)\right|^{2}\right)
$$

and

$$
f\left(y_{n}\right)=f^{\prime}\left(x^{*}\right)\left(y_{n}-x^{*}\right)+\frac{f^{\prime \prime}\left(x^{*}\right)}{2}\left(y_{n}-x^{*}\right)^{2}+o\left(\left|\left(y_{n}-x^{*}\right)\right|^{2}\right)
$$

By applying the mean value theorem to $f$, replacing $f\left(x_{n}\right)$ and $f\left(y_{n}\right)$ by their values in (11), and then using Theorem 1 we have:

$$
x_{n+1}-x^{*}=\left(y_{n}-x^{*}\right)\left(x_{n}-x^{*}\right) \frac{f^{\prime \prime}\left(x^{*}\right)}{2 f^{\prime}\left(\delta_{n}\right)}+\epsilon_{n}
$$

where:

$$
\epsilon_{n}=\frac{\left(x_{n}-x^{*}\right) o\left(\left|\left(y_{n}-x^{*}\right)\right|^{2}\right)-\left(y_{n}-x^{*}\right) o\left(\left|\left(x_{n}-x^{*}\right)\right|^{2}\right)}{f^{\prime}\left(\delta_{n}\right)\left(y_{n}-x_{n}\right)}
$$

Setting $y_{n}-x_{n}=\left(y_{n}-x^{*}\right)-\left(x_{n}-x^{*}\right)$, factoring by $\left(x_{n}-x^{*}\right)$, and using theorem 1 , we obtain: 


$$
\epsilon_{n}=\frac{o\left(\left|\left(y_{n}-x^{*}\right)\right|^{2}\right)-\left(y_{n}-x^{*}\right) \frac{o\left(\mid\left(x_{n}-x^{*}\right)^{2}\right)}{x_{n}-x^{*}}}{f^{\prime}\left(\delta_{n}\right)\left(\frac{y_{n}-x^{*}}{x_{n}-x^{*}}-1\right)} \rightarrow 0
$$

Therefore, by theorem 1, we have: $\left|y_{n}-x^{*}\right| \leq C_{1}\left|x_{n}-x^{*}\right|^{2}$ and $m \leq\left|f^{\prime}\left(\delta_{n}\right)\right|$. Thus by using (12) and (13), we finally have:

$$
\left|x_{n+1}-x^{*}\right| \simeq C_{2}\left|\left(x_{n}-x^{*}\right)\right|^{3}
$$

where $C_{2}=\frac{K^{2}}{2 m^{2}}(1+|h| M)$

\section{Numerical Experiments}

In this section, we will give some numerical experiments for the purpose of comparing this new method based on nonlinear hybrid procedures with Newton's method and Secant method. These methods will be denoted respectively by M.PHNL, M.NWT. and M.SEC.. For the different examples, the comparison will be summarized in tables which give the number of iterations, the absolute value of the associated residue and the time to converge to the optimal solution for each method.

\section{Example 1.}

We consider the function:

$$
f(x)=e^{x}-1.5-\tan ^{-1}(x)
$$

where $x_{0}=-7, \epsilon=10^{-16}$

Table 1. Numerical results of example 1

\begin{tabular}{lccc}
\hline Iterations & M.PHNL & M.NEW. & M.SEC \\
\hline 1 & 0.0223 & 0.0223 & 0.0223 \\
2 & 0.0043 & 0.0044 & 0.0187 \\
3 & $2.2608 \mathrm{D}-04$ & $2.3902 \mathrm{D}-04$ & 0.0013 \\
4 & $7.1204 \mathrm{D}-07$ & $7.9958 \mathrm{D}-07$ & $1.1673 \mathrm{D}-04$ \\
5 & $7.1008 \mathrm{D}-16$ & $9.0083 \mathrm{D}-12$ & $2.1567 \mathrm{D}-06$ \\
6 & & 0 & $3.5415 \mathrm{D}-09$ \\
7 & & & $1.0747 \mathrm{D}-13$ \\
8 & & & 0 \\
CPU & $0.010168 \mathrm{~s}$ & $0.010284 \mathrm{~s}$ & $0.010344 \mathrm{~s}$ \\
\hline
\end{tabular}

\section{Example 2.}

We consider the function:

$$
f(x)=\cos (x)-x e^{x}+x^{2}
$$

where $x_{0}=0, \epsilon=10^{-16}$

Table 2. Numerical results of example 2

\begin{tabular}{lccc}
\hline Iterations & M.PHNL & M.NEW. & M.SEC \\
\hline 1 & 1 & 1 & 1 \\
2 & 0.2684 & 1.1780 & 0.0163 \\
3 & 0.0026 & 0.2218 & $7.7020 \mathrm{D}-04$ \\
4 & $2.4830 \mathrm{D}-09$ & 0.0134 & $4.0829 \mathrm{D}-06$ \\
5 & $1.1102 \mathrm{D}-16$ & $5.7482 \mathrm{D}-05$ & $1.0179 \mathrm{D}-09$ \\
6 & & $1.0692 \mathrm{D}-09$ & $1.2768 \mathrm{D}-15$ \\
7 & & $1.1102 \mathrm{D}-16$ & $1.1102 \mathrm{D}-16$ \\
$\mathrm{CPU}$ & $0.008762 \mathrm{~s}$ & 0.008949 & 0.010741 \\
\hline
\end{tabular}

\section{Example 3.}

We consider the function:

$$
f(x)=\sin (2 x)-1+x
$$

where $x_{0}=0.7, \epsilon=10^{-16}$ 
Table 3. Numerical results of example 3

\begin{tabular}{lccc}
\hline Iterations & M.PHNL & M.NEW. & M.SEC \\
\hline 1 & 0.4435 & 0.4435 & 0.4435 \\
2 & 0.0014 & 0.0222 & 0.4707 \\
3 & $4.3761 \mathrm{D}-10$ & $9.6837 \mathrm{D}-05$ & 0.0956 \\
4 & $5.5511 \mathrm{D}-16$ & $1.9069 \mathrm{D}-09$ & 0.0148 \\
5 & & $5.511 \mathrm{D}-16$ & $3.0644 \mathrm{D}-04$ \\
6 & & & $9.1552 \mathrm{D}-07$ \\
7 & & & $5.7072 \mathrm{D}-11$ \\
8 & & & $5.5511 \mathrm{D}-16$ \\
$\mathrm{CPU}$ & $0.013363 \mathrm{~s}$ & $0.011394 \mathrm{~s}$ & $0.018114 \mathrm{~s}$ \\
\hline
\end{tabular}

Example 4. (Annuity Rate)

The objective is to compute the average annuity rate $I$ of an investment fund for many years. We invest in a fund of $V=1000$ euros annually. After 5 years we have an amount of $M=6000$ euros. The relation between those three parameters $M, V, I$ and the number of years $n$ is as follows:

$$
M-V \frac{1+I}{I}\left[(1+I)^{n}-1\right]=0
$$

The problem is represented as a nonlinear equation, of which we are not able to found an exact solution. We consider the function:

$$
f(I)=6000-1000 \frac{1+I}{I}\left((1+I)^{5}-1\right)
$$

where: $I_{0}=0.05, \epsilon=10^{-16}$

Table 4. Numerical results of example 4

\begin{tabular}{lccc}
\hline Iterations & M.PHNL & M.NEW. & M.SEC \\
\hline 1 & 0.4435 & 0.4435 & 0.4435 \\
2 & 0.0014 & 0.0222 & 0.3689 \\
3 & $4.3761 \mathrm{D}-10$ & $9.6837 \mathrm{D}-05$ & $6.7256 \mathrm{D}-04$ \\
4 & $5.5511 \mathrm{D}-16$ & $1.9069 \mathrm{D}-09$ & $1.8270 \mathrm{D}-08$ \\
5 & & $5.511 \mathrm{D}-16$ & $2.7284 \mathrm{D}-12$ \\
6 & & & $1.0913 \mathrm{D}-11$ \\
7 & & & $4.5474 \mathrm{D}-12$ \\
8 & & & $8.1854 \mathrm{D}-12$ \\
9 & & & $1.8189 \mathrm{D}-12$ \\
10 & & & $9.0949 \mathrm{D}-13$ \\
CPU & $0.014224 \mathrm{~s}$ & $0.015270 \mathrm{~s}$ & $0.008676 \mathrm{~s}$ \\
\hline
\end{tabular}

\section{Conclusions}

Throughout these examples, the methods based on nonlinear hybrid procedures give better results and have shown their efficiency. Moreover, they have a convergence at least quadratic, don't use the derivative in each iteration and easy to manipulate.

\section{References}

Brezinski, C., \& Chehab, J.-P. (1998). Nonlinear hybrid procedures and fixed point iterations. Numerical Functional Analysis and Optimization, 19(5-6), 465-487. https://doi.org/10.1080/01630569808816839

Chun, C. (2007). A geometric construction of iterative functions of order three to solve nonlinear equations. Computers $\mathcal{E}$ Mathematics with Applications, 53(6), 972-976. https://doi.org/10.1016/j.camwa.2007.01.007

Dennis, J. E., \& Schnabel, R. B. (1996). Numerical methods for unconstrained optimization and nonlinear equations. Philadelphia: Soc. for Industrial and Applied Mathematics. https://doi.org/10.1137/1.9781611971200

Frontini, M., \& Sormani, E. (2003). Modified Newtons method with third-order convergence and multiple roots. Journal of Computational and Applied Mathematics, 156(2), 345-354. https://doi.org/10.1016/S0377-0427(02)00920-2 
Ortega, J. M., \& Rheinboldt, W. C. (2000). Iterative solution of nonlinear equations in several variables. Philadelphia (Pa.): Society for industrial and applied mathematics. https://doi.org/10.1137/1.9780898719468

Rhanizar, B. (1999). Hybrid procedures for solving some unconstrained nonlinear optimization problems. Applied Numerical Mathematics, 30(4), 459-474. https://doi.org/10.1016/S0168-9274(98)00068-3

\section{Copyrights}

Copyright for this article is retained by the author(s), with first publication rights granted to the journal.

This is an open-access article distributed under the terms and conditions of the Creative Commons Attribution license (http://creativecommons.org/licenses/by/4.0/). 